\title{
Surface Design and Numerical Control Simulation of Complex Parts
}

\author{
Xiaohui Wu \\ College of Mechanical Engineering, Jilin Teacher's Institute of Engineering and Technology, \\ Changchun, Jilin, china 130052 \\ xh0916@126.com
}

Keywords: Complex parts; Surface design; Numerical control; Simulation processing

\begin{abstract}
Through the complex parts of Coca Cola bottle bottom surface design, elaborated according to the line of surface feature different combinations of the different surface generation and the corresponding surface editing should be in the surface structure can be obtained complex curved surface parts model. Proposed complex parts surface design problems. The processing parameters were adjusted to optimize research, choosing the optimal parameters, and automatic programming and machining simulation, to meet the processing requirements.
\end{abstract}

\section{Introduction}

With the development of science and technology, surface is engineering the most complex and often applied shape, in aviation, shipbuilding, automobile, power, energy, and other departments in many parts of the shape, such as an aircraft wing, automobile, mold work piece surface belong to the curved surface. More and more of these complex shape parts, precision requirements are also getting higher and higher. How accurate, efficient design and manufacturing surfaces become must solve the problem. [1]

Computer aided design and computer aided manufacturing technology, is a use of computer technology as the main means, through the generation and use of various digital information and graphic information, to help people complete the product design and manufacturing technology. The development and application level of this technology has become the measure of a national science and technology and the industry modernization.[2] The actual application results aided manufacturing technology of computer aided design and computer is: to optimize the overall scheme, optimization of process parameters, improve product design quality, shorten the product design and manufacturing cycle, resulting in significant social and economic benefits. At present, the manufacturing technology of computer aided design and computer aided are widely used in automotive, aerospace, mechanical and electrical. Light industry and other fields. Therefore, the study of complex surface parts design and simulation process is very necessary. [3]

\section{Curved Surface Design of Complex Parts}

Using CAXA Manufacturing Engineer 2011 to carry on the Coca-Cola bottle bottom surface design and the simulation processing. [4]

Rectangular Drawing. Into the CAXA Manufacturing Engineer 2011 model window,press the F7 key drawing plane switching to XOZ plane. [5] Click curve generation Toolbar "Rectangle" button with the left mouse button pickup to the coordinate origin, drawing a $42.5 * 37$ rectangular, the result is as shown in Fig. 1. 


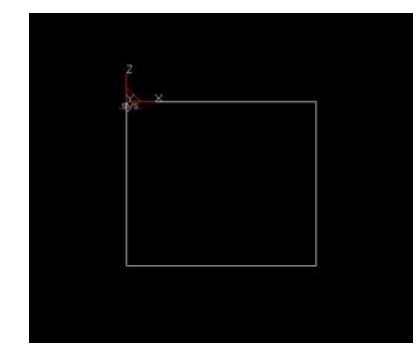

Figure 1. rectangular drawing

Generated Dimension. Click the "isometric line" button in the toolbar to generate the various isometric lines as shown in the following figure, as shown in Fig. 2.

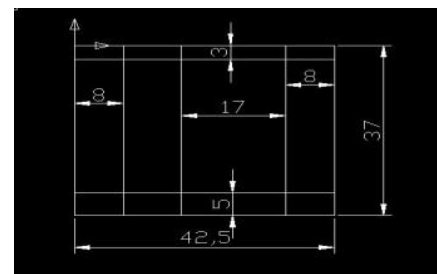

Figure 2. Generated dimension

Generating a Circular Arc, a Straight Line Section. Click the "cut" button in the curve editor to cut the "arc" button in the toolbar, click the "straight line" button, and enter the space curve to draw the state, generate the arc and a straight line as shown in Fig. 3. [6]

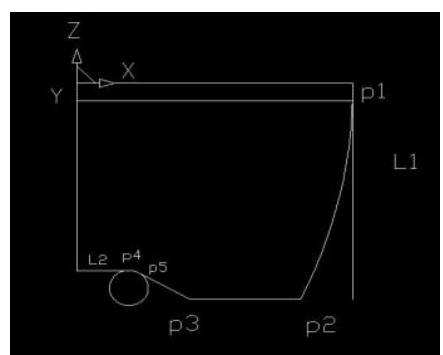

Figure 3. generates arcs and straight lines

Generate Round and Cut. Click curve generation Toolbar "circle" button, in the menu immediately below the feature tree selection "two radius", with the left mouse button pickup P5 point, and then press the spacebar, in the pop-up point tools menu select "point of tangency" command, pickup round $\mathrm{R} 6$, input radius of 6 , generation is tangent to the circle $\mathrm{R} 6 \mathrm{P} 5$, radius of 6 circle $\mathrm{C} 1$; in much the same way as for with arc tangent $\mathrm{C} 4$, the intersection of the line (L3 and arc C4, radius of 6 round $\mathrm{C} 2$ and and circle $\mathrm{C} 1$ and $\mathrm{C} 2$ tangent and radius of 50 round $\mathrm{C} 3$ and cutting, the results as shown in the Fig. 4 .

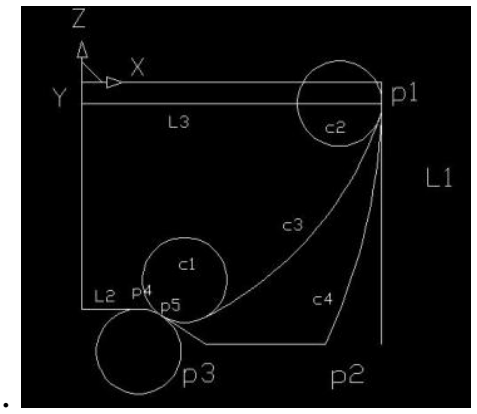

Figure 4. Generating circle 
Geometric Transformation. Click on the "cutting" and "delete" button, remove the unwanted part. The drawing plane switching to the XOY plane, click the geometry transform "plane rotate button, immediately menu, select" copy "mode, the input angle 41.6, origin of coordinates of pickup as the center to rotate, then the box all selected lines, click the right button to confirm the coke bottle bottom line shown on the diagram frame diagram Cola bottle at the end of 5 the same part, so that the completion of a part of the section line, through the array can get all the section line. [7]

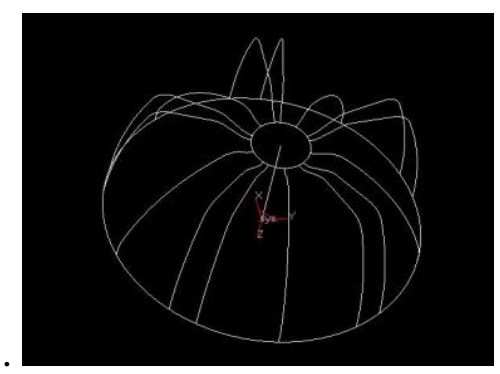

Figure 5. Generating circle

Surface Generation of Coke Bottle Bottom. The surface of coke bottle bottom is formed by using grid surface and straight line, as shown in Fig. 6.

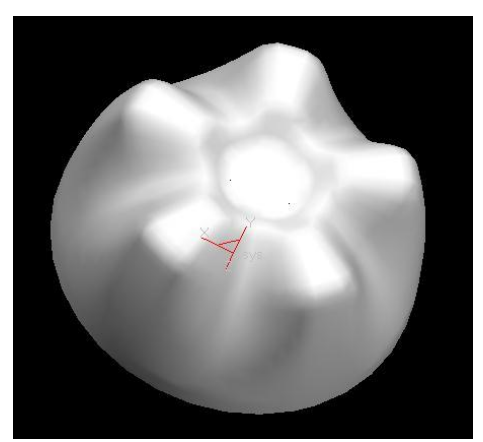

Figure 6. Coke bottle bottom surface generation

\section{NC Machining Simulation}

In CAXA Manufacturing Engineer 2011 modeling window to complete the bottom of the coke bottle shape. In the CAXA Manufacturing Engineer 2011 processing interface selection contour rough machining and contour precision machining, simulation and processing. [8]

\section{Define Blank.}

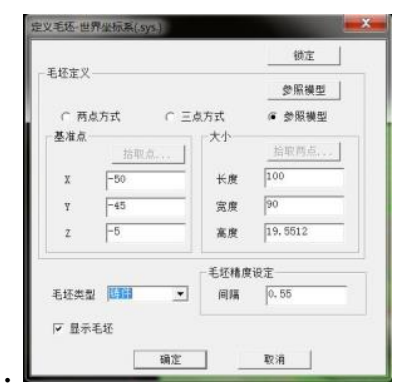

Figure 7. define blank

Contour Rough Machining Simulation. Rough machining simulation is obtained by setting various parameters as shown in Fig. 8. [9] 


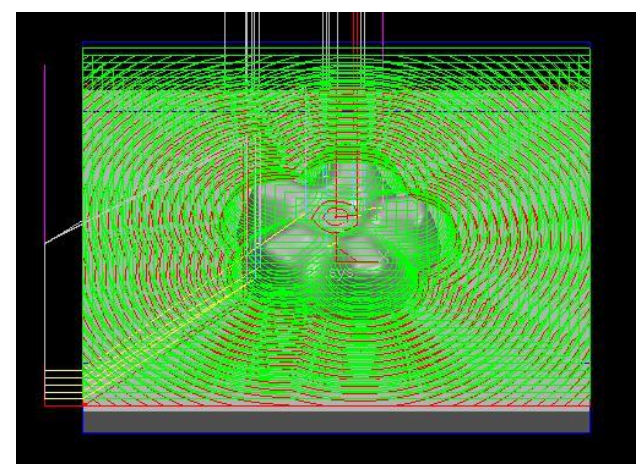

Figure 8. Rough machining simulation

Contour Precision Machining Simulation. By setting various parameters to get the precision machining simulation as shown in Fig. 9.

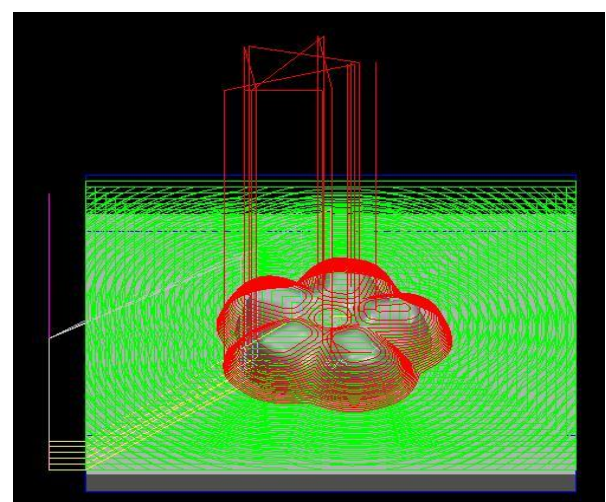

Figure 9. Precision machining simulation

\section{Concluding Remarks}

Through the complex parts of Coca Cola bottle bottom surface design, elaborated according to the line of surface feature different combinations of the different surface generation and the corresponding surface editing should be in the surface structure can be obtained by model of complex curved surface parts. Of machining parameters were adjusted optimization research, choosing the optimal parameters, and automatic programming and machining simulation, meet the requirement of processing precision, and at the same time, improve the machining productivity. [10] But surface modeling design also limitations, describe the outer surface of the entity only, not open objects and display the internal structure. Therefore, it is not possible to say the steric properties of the complex parts. To the quality characteristics of an object analysis problems.

\section{References}

[1] Z.D. Wei: SolidWorks Surface Design Example(Machinery Industry Press, China 2012). (In Chinese)

[2] W. Lei: Electronic technology and software engineering, (2014) No.01,p.99 (In Chinese)

[3] J.Y.and G.H. Xu: numerical control processing technology and programming (National Defence Industry Press, china 2010). (In Chinese)

[4] Y.M. Pu and F.Jiang: numerical control milling and processing practical technique( Mechanical Industry Press,china 2010). (In Chinese)

[5] X.B.Yang and G.H.Luo :CAD/CAM application technology(National Defence Industry Press, china 2014). (In Chinese) 
[6] Z.Wen and J.Z.Wei:NX6.0 UG numerical control processing(People's Posts and Telecommunications Press, china 2008). (In Chinese)

[7] W.Xu and S. Tan:Simulation and practice of CNC machine tools( Publishing House of electronics industry, china 2009).

[8] Chua, C.K. , Teh, S.H. , Gay, R.K.L.:Rapid prototyping versus virtual prototyping in product design and manufacturing(International Journal of Advanced Manufacturing Technology, 2009:15-8)

[9] [9] Terzopoulos D and Gossard D. :Dynamic NURBS with Geometric Constraints for Interactive Sculpting(ACM, Transactions on Graphics, 2004, 13(2): 103-136)

[10] Moreton H P and Sequin C H. :Functional Optimization for Fair Sruface Design(Computer Graphics,2002,26(2): 167-175) 